\title{
The differences in temperament-character traits, suicide attempts, impulsivity, and functionality levels of patients with bipolar disorder I and II
}

This article was published in the following Dove Press journal:

Neuropsychiatric Disease and Treatment

18 January 2016

Number of times this article has been viewed

Filiz |zci'

Ebru Kanmaz Fındıklı²

Serkan Zincir ${ }^{3}$

Selma Bozkurt Zincir ${ }^{4}$

Merve Iris $\mathrm{Koc}^{4}$

'Department of Psychiatry, School of Medicine, Istanbul Bilim University, Istanbul, ${ }^{2}$ Department of Psychiatry,

School of Medicine, Kahramanmaras Sutcu Imam University,

Kahramanmaras, ${ }^{3}$ Department of Psychiatry, Kocaeli Gölcük Military Hospital, Kocaeli, ${ }^{4}$ Department of Psychiatry, Erenköy Training and Research Hospital for Psychiatric and Neurological Disorders, Istanbul, Turkey
Correspondence: Filiz Izci

Department of Psychiatry, School of Medicine, Istanbul Bilim University, I64 Abide-i Hurriyet Cad, Istanbul 34I00, Turkey

Tel +9050545030l3

Email filizizci@yahoo.com
Background: The primary aim of this study was to compare the differences in temperamentcharacter traits, suicide attempts, impulsivity, and functionality levels of patients with bipolar disorder I (BD-I) and bipolar disorder II (BD-II).

Methods: Fifty-two BD-I patients and 49 BD-II patients admitted to Erenköy Mental and Neurological Disease Training and Research Hospital psychiatry clinic and fifty age- and sexmatched healthy control subjects were enrolled in this study. A structured clinical interview for Diagnostic and Statistical Manual of Mental Disorders, 4th Edition Axis I Disorders, Temperament and Character Inventory, Barrett Impulsiveness Scale-11 (BIS-11), Hamilton Depression Inventory Scale, Young Mania Rating Scale, and Bipolar Disorder Functioning Questionnaire (BDFQ) were administered to patients and to control group.

Results: No statistically significant difference in sociodemographic features existed between the patient and control groups $(P>0.05)$. Thirty-eight subjects $(37.62 \%)$ in the patient group had a suicide attempt. Twenty-three of these subjects $(60.52 \%)$ had BD-I, and 15 of these subjects $(39.47 \%)$ had BD-II. Suicide attempt rates in BD-I and II patients were $60.52 \%$ and $39.47 \%$, respectively $(P<0.05)$. Comparison of BD-I and II patients with healthy control subjects revealed that cooperativeness (C), self-directedness (Sdi), and self-transcendence (ST) scores were lower and novelty seeking (NS1 and NS2), harm avoidance (HA4), and reward dependence (RD2) subscale scores were higher in patients with BD-I. When BD-I patients were compared with BD-II patients, BIS-11 (attention) scores were higher in patients with BD-II and BIS-11 (motor and nonplanning impulsivity) scores were higher in patients with BD-I. According to BDFQ, relations with friends, participation in social activities, daily activities and hobbies, and occupation subscale scores were lower and taking initiative subscale scores were higher in patients with BD-I. Social withdrawal subscale scores were higher in patients with BD-II.

Conclusion: In our study, NS, HA, and RD scores that may be found high in suicide attempters and Sdi scores that may be found low in suicide attempters were as follows: NS1, NS2, HA4, and RD2 subscale scores were high and Sdi scores were low in patients with BD-I, suggesting a higher rate of suicide attempts in this group of patients. In addition, $\mathrm{C}$ and Sdi scores that indicate a predisposition to personality disorder were significantly lower in patients with BD-I than patients with BD-II and healthy controls, suggesting a higher rate of personality disorder comorbidity in patients with BD-I. Higher impulsivity and suicidality rates and poorer functionality in patients with BD-I also suggest that patients with BD-I may be more impulsive and more prone to suicide and have poorer functionality in some areas.

Keywords: bipolar disorder I and II, temperament and character, suicide, impulsivity, functionality 


\section{Introduction}

Bipolar disorder (BD) is a mental disorder characterized by manic, depressive, and mixed episodes, and life-expectancy has been found to be much shorter in patients, with BD prevalence of BD-I and BD-II being $0.8 \%$ and $0.5 \%$ respectively. ${ }^{1,2}$ $\mathrm{BD}$ is divided into BD-I, BD-II, cyclothymic disorder, and BD not otherwise specified (NOS) subgroups according to Diagnostic and Statistical Manual of Mental Disorders, 4th Edition (DSM-IV) classification system. ${ }^{3}$ In a study examining Bipolar spectrum disorders among 300 patients, BD rate was found to be high and a majority of the BD cases had BD-II. ${ }^{4}$ The presence of other Axis I disorders, alcohol and substance use, rapid cycling, early onset of bipolar, a family history of suicide attempts, and severe mixed and depressive episodes may constitute risk factors for suicide attempts in patients with BD. ${ }^{5}$ Patients with $\mathrm{BD}$ have a suicide rate that is 30 times higher than the general population, and $15 \%-25 \%$ of bipolar patients attempt suicide. Fifteen percent of those who attempted suicide succeed in ending their lives. ${ }^{6}$ Although no difference exists in attempted suicide rates between BD-I and BD-II patients, BD-II patients tend toward more lethal suicide attempts. ${ }^{7}$

Personality disorder comorbidity in patients with psychiatric disorders has been reported to increase the risk of suicide. ${ }^{8,9}$ Personality traits are among the many predictors of suicide in patients with BD. ${ }^{10}$ Cloninger has developed a dimensional psychobiological model of personality that accounts for two major components of personality: temperament and character traits. Cloninger's psychobiological theory of personality contains four temperament dimensions including novelty seeking (NS), harm avoidance (HA), reward dependence (RD), and persistence (P) along with three character dimensions including self-directedness (Sdi), cooperativeness (C), and self-transcendence (ST). Temperament dimensions reflect biological, hereditary aspects of personality. Temperament is distinguished from character by individual differences in interpersonal relationships and object relations. Meanwhile, life events, culture, and social learning mold character dimensions. ${ }^{11-14} \mathrm{BD}$ patients have higher novelty-seeking scores and lower persistence scores than depressive patients and normal subjects. ${ }^{15,16}$ Higher NS scores may predict impaired functioning. ${ }^{17}$ In addition, current research findings show that specific temperament types (depressive, cyclothymic, hyperthymic, irritable, and anxious) are the subsyndromal (trait-related) manifestations and commonly the antecedents of minor and major mood disorders. Up to $20 \%$ of the population has some kind of marked temperaments; depressive, cyclothymic, and anxious temperament is more frequent in women, whereas hyperthymic and irritable temperaments predominate among men. Premorbid temperament types have an important role in the clinical evolution of minor and major mood episodes including the direction of the polarity and the symptom formation of acute mood episodes. They can also significantly affect the long-term course and outcome including suicidality and other forms of self-destructive behaviors. ${ }^{18}$ More than $81 \%$ of the patients with prevailing cyclothymic-depressiveanxious temperament had mild-to-severe suicidal risk on the MINI versus only around $42 \%$ of the patients with prevailing hyperthymic temperament. ${ }^{19}$ Here, we aimed to compare a history of attempted suicide, temperament character traits, impulsivity, and levels of functionality in BD-I and BD-II patients admitted to our outpatient clinic.

\section{Patients and methods}

\section{Sample}

Fifty-two patients diagnosed with BD-I and 49 patients diagnosed with BD-II using a structured interview for DSM-IV Axis I Disorders (SCID-I/CV) who were admitted to the outpatient psychiatry clinic of the Erenköy Mental and Neurological Diseases Training and Research Hospital between March 2013 and August 2013 were enrolled in this study. Also 50 age- and sex-matched healthy control subjects who met the study criteria and had no history of any psychiatric or neurological disease were included. Verbal and written informed consent was taken from the patient and control group. The study was started after the approval of Ethics Committee of Erenköy Psychiatric and Neurological Diseases Training and Research Hospital.

Individuals who were between 18 and 60 years old, literate enough to understand written documents, diagnosed with BD according to Diagnostic and Statistical Manual of Mental Disorders, 4th Edition, Text Revision (DSM-IV-TR), in remission at least for 2 months with a Hamilton Rating Score of Depression (HRSD) lower than 7, and a Young Mania Rating Scale(YMRS) score lower than 5 were included. Impulsivity and temperament characteristics were evaluated during remission.

We excluded from the study patients with mental retardation, alcohol and drug-abuse related disorders, anxiety disorders, schizophrenia and other psychotic disorders, dementia and other cognitive disorders, and neurological disorders with unique personality traits such as epilepsy, migraine, multiple sclerosis, and Parkinson's disease, as well as systemic disorders leading to cognitive impairment or affecting vision, hearing, or motor skills.

\section{Materials}

We assessed all patients and controls using a semistructured sociodemographic data form based on clinical experience 
and an investigation of the literature, structured clinical interview for DSM-IV SCID-I, Temperament and Character Inventory (TCI), and Barratt Impulsivity Scale 11 (BIS-11). Additionally, Hamilton Depression Rating Scale, YMRS, and Bipolar Disorder Functioning Questionnaire (BDFQ) were administered to the patient group.

\section{Data collection tools}

\section{Sociodemographic and clinical information}

Sociodemographic and clinical information was collected using a questionnaire consisting of some questions regarding age, sex, marital status, educational level, and economic status, for patients with BD-I, BD-II, and the control group.

\section{Structured Clinical Interview for DSM-IV/Clinical Version}

This structured interview was developed by First et $\mathrm{al}^{20}$ in 1995 to determine the presence or absence of DSM-IV Axis I disorders. Çorapçıŏlu conducted a validation and reliability study for the Turkish version in $1999 .{ }^{21}$

\section{Temperament and Character Inventory}

The TCI is a 240-item, self-report questionnaire with trueor-false statements developed to assess personality. The TCI consists of seven higher-order scales. The temperament dimensions of NS, HA, and RD are each divided into four subscales, while the character dimensions of Sdi and cooperativeness $(\mathrm{C})$ are each divided into five subscales. In addition, ST is divided into three subscales. ${ }^{11}$ Köse et al $^{22}$ conducted the validation and reliability study for the Turkish version of the inventory in 2004.

\section{Barratt Impulsiveness Scale- I I}

This is a 30 -item self-report measure intended to assess impulsivity in which the individual marks the most appropriate answers to a series of questions from the alternatives, "rarely/never, occasionally, often, and almost always/ always." A factor analysis indentified three second-order factors: 1) attentional impulsivity, 2) motor impulsivity, and 3) nonplanned impulsivity. Higher scores indicate higher levels of impulsivity. ${ }^{23}$ Güleç et $\mathrm{al}^{24}$ conducted the validation and reliability study for the Turkish version in 2008 .

\section{Hamilton Rating Scale for Depression}

This is the most widely used scale for assessing depression severity and was developed by Williams in $1978 .{ }^{25}$ The sum of the scores obtained from each item provide the total score. Scores below 7 indicate no depression, scores between 7 and 17 indicate moderate depression, scores between 18 and 24 indicate heavy depression, and scores $\geq 25$ indicate severe depression. Akdemir et $\mathrm{al}^{26}$ conducted the validation and reliability study for the Turkish version in 1996.

\section{Young Mania Rating Scale}

Young et $\mathrm{al}^{27}$ developed this scale, which is widely used to assess the intensity of manic symptoms. The scale consists of eleven items. Seven of them have five Likert-type items and four of them have nine Likert-type items. The lowest score that can be obtained from the scale is 0 , while the highest score is 44 . The validity and reliability of the Turkish version has been tested by Karadağ et al. ${ }^{28}$ The cut-off score was not calculated during the Turkish version's validity and reliability study. Here, we compared both total scores and single-item scores according to sex.

\section{Bipolar Disorder Functioning Questionnaire (BDFQ)}

This is a 52-item self-report measure intended to assess the functionality of bipolar patients during symptomatic periods or recovery. Aydemir et $\mathrm{al}^{29}$ developed the questionnaire that consists of eleven subscales, including emotional functioning, intellectual functioning, sexual functioning, stigmatization feelings, social withdrawal, household relations, relations with friends, participation in social activities, daily activities and hobbies, initiative taking, self-sufficiency, and occupation. Because the cut-off score could not be calculated, it was recommended for use in comparative studies. $^{29}$

\section{Statistical analysis}

"SPSS for Windows 8.0" (SPSS Inc., Chicago, IL, USA) was used for data analysis. Chi-square test was used to evaluate the relationship between categorical variables. After testing for homogeneity and normality of variances, Student's $t$-test was performed to evaluate the difference between temperament and impulsivity. One-way analysis of variance (ANOVA) and Tukey post hoc test were performed to evaluate the patient subgroups. Results were evaluated at $95 \%$ confidence interval and significance was evaluated at $P<0.05$.

\section{Results}

Fifty-two patients diagnosed with BD-I and 49 patients diagnosed with BD-II according to the DSM-IV-TR and 50 age- and sex-matched controls were enrolled in this study. The mean age in the patient and control groups was $35.69 \pm 12.10$ years and $32.00 \pm 9.24$ years, respectively. There was no statistically significant difference between the patient and control groups in terms of sociodemographic properties $(P>0.05$; Table 1$)$. Thirty-eight $(37.62 \%)$ subjects in the 
Table I Sociodemographic characteristics of the patients and controls

\begin{tabular}{|c|c|c|c|c|}
\hline & \multirow{2}{*}{$\begin{array}{l}\text { Patient } \\
(\mathbf{N}=\mid 0 I)\end{array}$} & \multirow{2}{*}{$\begin{array}{l}\text { Control } \\
(\mathbf{N}=\mathbf{5 0})\end{array}$} & \multicolumn{2}{|c|}{ Statistic } \\
\hline & & & $x^{2}$ & $P$-value \\
\hline Age (mean $\pm S D)$ & $35.69 \pm 12.10$ & $32.00 \pm 9.24$ & 1.89 & $0.06 *$ \\
\hline \multicolumn{5}{|l|}{ Sex } \\
\hline Male & 7I (70.3) & $30(60.0)$ & 1.60 & $0.20 *$ \\
\hline Female & $30(29.7)$ & $20(40.0)$ & & \\
\hline \multicolumn{5}{|c|}{ Educational status } \\
\hline Primary school & $34(33.6)$ & $8(16.0)$ & & \\
\hline High school & $32(3 \mid .7)$ & $15(30.0)$ & 5.40 & $0.06 *$ \\
\hline University & 35 (34.7) & $27(54.0)$ & & \\
\hline \multicolumn{5}{|l|}{ Marital status } \\
\hline Married & $41(40.6)$ & $18(36.0)$ & & \\
\hline Single & $60(59.4)$ & $32(64.0)$ & 1.60 & $0.20 *$ \\
\hline \multicolumn{5}{|c|}{ Occupational status } \\
\hline Employed & $67(66.3)$ & $30(60.0)$ & & \\
\hline Unemployed & $27(26.7)$ & $10(20.0)$ & 10.94 & $0.06 *$ \\
\hline Student & $7(6.90)$ & $10(20.0)$ & & \\
\hline
\end{tabular}

Notes: $* P>0.05$. Data presented as number $(\%)$.

Abbreviation: SD, standard deviation.

patient group had a suicide attempt and $23(60.52 \%)$ of these patients were diagnosed with BD-I and 15 (39.47\%) were diagnosed with BD-II (Table 2).

Suicide attempt rates of BD-I and BD-II patients were $60.52 \%$ and $39.47 \%$, respectively $(P<0.05$; Table 2$)$.

Within temperament dimension, in the comparison of the patients with BD-I, BD-II, and healthy controls, there was a statistically significant difference between the groups in terms of NS (NS1 and NS2; respectively: $F=6.17, P<0.05$; $F=16.32, P<0.00)$, HA4 ( $F=6.83, P<0.05)$, and RD (RD2; $F=8.80, P<0.01)$.

Within character dimension, in the comparison of the patients with BD-I, BD-II, and healthy controls, there was a statistically significant difference between the groups in terms of Sdi subgroups (Sdi1, Sdi2, Sdi3, Sdi5; $F=11.72, P<0.05$; $F=23.05, P<0.00 ; F=14.64, P<0.00 ; F=19.97, P<0.00)$, total Sdi $(F=17.55, P<0.00)$, C subgroups (C1, C2, C3, C4, C5; respectively, $F=7.36, P<0.05 ; F=6.68, P<0.05, F=13.13$, $P<0.00 ; F=6.11, P<0.05, F=12.69, P<0.00)$, and total $\mathrm{C}$ scores $(\mathrm{C} ; F=17.55, P<0.00)$. In the comparison of patients

Table 2 Comparison of suicide attempt rates of patients with BD-I and BD-II

\begin{tabular}{|c|c|c|c|c|}
\hline & \multirow{2}{*}{$\begin{array}{l}\text { The group of } \\
\text { patients with } \\
\text { BD-I }(\mathbf{N}=\mathbf{5 2})\end{array}$} & \multirow{2}{*}{$\begin{array}{l}\text { The group of } \\
\text { patients with } \\
\text { BD-II }(\mathbf{N}=49)\end{array}$} & \multicolumn{2}{|c|}{ Statistic } \\
\hline & & & $\chi^{2}$ & $P$-value* \\
\hline $\begin{array}{l}\text { Suicide attempt }(+) \text {, } \\
(\mathrm{N}, \%)\end{array}$ & $23(60.52)$ & I 5 (39.47) & & \\
\hline $\begin{array}{l}\text { Suicide attempt }(-) \text {, } \\
(\mathrm{N}, \%)\end{array}$ & 29 (46.03) & 34 (53.96) & 1.70 & 0.019 \\
\hline
\end{tabular}

Note: $* p<0.05$

Abbreviations: BD-I, bipolar disorder I; BD-II, bipolar disorder II. with BD-I, BD-II, and healthy controls, there was a statistically significant difference between the groups in terms of ST subgroups (ST1, ST2; respectively, $F=9.91, P<0.00 ; F=15.66$, $P<0.00)$ and total ST scores $(F=8.43, P<0.00$; Table 3$)$.

According to the BIS-11, motor impulsiveness and nonplanning impulsiveness subgroup scores were found to be statistically significantly higher in patients with BD-I (respectively, $F=21.04, P<0.00 ; F=23.88, P<0.00$ ). However, attentional impulsiveness subgroup score was

Table 3 Comparison of TCl scores of patients with BD-I, BD-II, and healthy controls

\begin{tabular}{|c|c|c|c|c|c|}
\hline & \multirow{2}{*}{$\begin{array}{l}\text { BD-I } \\
(\mathbf{N}=52)\end{array}$} & \multirow{2}{*}{$\begin{array}{l}\text { BD-II } \\
(\mathbf{N}=49)\end{array}$} & \multirow{2}{*}{$\begin{array}{l}\text { Controls } \\
(\mathbf{N}=50)\end{array}$} & \multicolumn{2}{|c|}{ Statistics } \\
\hline & & & & $F^{a}$ & $P$-value \\
\hline \multicolumn{6}{|c|}{ Novelty seeking } \\
\hline NSI & $6.06 \pm 1.76$ & $5.3 I \pm 2.1 I$ & $6.34 \pm 2.03$ & 6.17 & $0.04 *$ \\
\hline NS2 & $4.88 \pm 2.02$ & $4.22 \pm 2.00$ & $3.14 \pm 1.97$ & 16.32 & $0.00 *$ \\
\hline NS3 & $5.48 \pm 2.35$ & $4.46 \pm 2.34$ & $4.88 \pm 1.49$ & 3.68 & 0.15 \\
\hline NS4 & $4.09 \pm 1.89$ & $4.24 \pm 1.92$ & $4.24 \pm I .66$ & 0.37 & 0.82 \\
\hline Total & $20.5 I \pm 8.02$ & $18.23 \pm 8.37$ & $18.60 \pm 4.83$ & 0.82 & 0.71 \\
\hline \multicolumn{6}{|c|}{ Harm avoidance } \\
\hline $\mathrm{HAI}$ & $6.18 \pm 2.32$ & $5.09 \pm 2.44$ & $5.02 \pm 2.05$ & 5.20 & 0.07 \\
\hline $\mathrm{HA} 2$ & $3.75 \pm 1.81$ & $3.72 \pm 1.54$ & $3.64 \pm 1.50$ & 0.39 & 0.81 \\
\hline HA3 & $3.42 \pm 2.35$ & $2.8 \mathrm{I} \pm 2.25$ & $3.08 \pm 1.38$ & 1.51 & 0.46 \\
\hline HA4 & $4.65 \pm 2.33$ & $4.26 \pm 1.91$ & $3.48 \pm 1.52$ & 6.83 & $0.03 *$ \\
\hline Total & $|8.00 \pm 8.8|$ & $15.88 \pm 8.14$ & $15.22 \pm 3.72$ & 2.73 & 0.24 \\
\hline \multicolumn{6}{|c|}{ Reward dependence } \\
\hline RDI & $6.68 \pm 2.16$ & $7.47 \pm 1.72$ & $7.37 \pm 1.66$ & 3.11 & 0.21 \\
\hline RD2 & $4.92 \pm 1.79$ & $4.21 \pm 1.65$ & $3.85 \pm 1.68$ & 8.80 & $0.01 *$ \\
\hline RD3 & $2.80 \pm 1.30$ & $2.45 \pm 1.20$ & $2.27 \pm 1.30$ & 4.41 & 0.11 \\
\hline Total & $14.40 \pm 3.69$ & $14.15 \pm 3.08$ & $13.56 \pm 2.66$ & 1.99 & 0.36 \\
\hline \multicolumn{6}{|c|}{ Persistence } \\
\hline$P$ & $4.8 \mathrm{I} \pm 1.86$ & $5.4 I \pm 2.53$ & $5.16 \pm 1.85$ & 0.82 & 0.66 \\
\hline \multicolumn{6}{|c|}{ Self-directedness } \\
\hline SDI & $4.19 \pm 1.86$ & $4.24 \pm 2.27$ & $5.58 \pm 1.73$ & 11.72 & $0.03 *$ \\
\hline SD2 & $4.86 \pm 1.58$ & $5.25 \pm 1.75$ & $6.58 \pm 1.57$ & 23.50 & $0.00 *$ \\
\hline SD3 & $2.66 \pm 1.39$ & $2.88 \pm 1.56$ & $3.78 \pm 1.09$ & 14.64 & $0.00 *$ \\
\hline SD4 & $5.24 \pm 2.81$ & $5.53 \pm 2.23$ & $5.76 \pm 2.55$ & 0.75 & 0.68 \\
\hline SD5 & $6.45 \pm 2.06$ & $6.61 \pm 2.38$ & $8.40 \pm 1.93$ & 19.97 & $0.00 *$ \\
\hline Total & $22.77 \pm 7.43$ & $24.72 \pm 8.16$ & $30.10 \pm 6.22$ & 17.55 & $0.00 *$ \\
\hline \multicolumn{6}{|c|}{ Cooperativeness } \\
\hline $\mathrm{Cl}$ & $5.29 \pm 2.00$ & $6.03 \pm 1.51$ & $6.46 \pm 1.40$ & 7.36 & $0.02 *$ \\
\hline C2 & $3.93 \pm 1.22$ & $4.16 \pm 1.26$ & $4.70 \pm 1.32$ & 6.68 & $0.03^{*}$ \\
\hline C3 & $4.34 \pm 1.45$ & $5.00 \pm 1.23$ & $5.48 \pm 1.18$ & 13.13 & $0.00 *$ \\
\hline C4 & $6.29 \pm 2.54$ & $7.75 \pm 1.64$ & $6.82 \pm 1.99$ & 6.11 & $0.04^{*}$ \\
\hline $\mathrm{C} 5$ & $6.42 \pm 1.58$ & $6.5 \mathrm{I} \pm \mathrm{I} .73$ & $7.54 \pm 1.03$ & 12.69 & $0.00 *$ \\
\hline Total & $26.27 \pm 8.79$ & $29.45 \pm 7.37$ & $31.00 \pm 4.12$ & 6.83 & $0.00 *$ \\
\hline \multicolumn{6}{|c|}{ Self-transcendence } \\
\hline STI & $6.30 \pm 2.76$ & $7.03 \pm 2.61$ & $5.26 \pm 2.34$ & 8.91 & $0.00 *$ \\
\hline ST2 & $5.23 \pm 2.14$ & $6.00 \pm 2.25$ & $4.06 \pm 1.95$ & 15.66 & $0.00 *$ \\
\hline ST3 & $7.06 \pm 2.66$ & $8.29 \pm 2.97$ & $7.30 \pm 3.11$ & 3.40 & 0.18 \\
\hline Total & $18.59 \pm 7.98$ & $21.32 \pm 7.83$ & $16.62 \pm 6.03$ & 8.43 & $0.00 *$ \\
\hline
\end{tabular}

Notes: $F$, ANOVA test value. aPost hoc assessment Tukey test. $* P<0.05$. Data presented as mean \pm standard deviation.

Abbreviations: BD-I, bipolar disorder I; BD-II, bipolar disorder II; ANOVA, analysis of variance; $\mathrm{TCl}$, temperament and character inventory. 
Table 4 Comparison of impulsivity in patients with BD-I and BD-II

\begin{tabular}{|c|c|c|c|c|c|}
\hline \multirow[t]{2}{*}{ BIS-I I } & \multirow{2}{*}{$\begin{array}{l}\text { Patients } \\
\text { with BD-I } \\
\text { (mean } \pm \text { SD) }\end{array}$} & \multirow{2}{*}{$\begin{array}{l}\text { Patients } \\
\text { with BD-II } \\
\text { (mean } \pm \text { SD) }\end{array}$} & \multirow[t]{2}{*}{ Controls } & \multicolumn{2}{|c|}{ Statistics } \\
\hline & & & & $F^{\mathrm{a}}$ & $P$-value \\
\hline & $70.80 \pm 23.24$ & $65.27 \pm 12.32$ & 57.08 & 22.17 & $0.00 *$ \\
\hline Nonplanned & $30.69 \pm 27.59$ & $25.02 \pm 4.92$ & $22.66 \pm 3.77$ & 23.88 & $0.00 *$ \\
\hline Motor & $23.00 \pm 5.36$ & $22.85 \pm 6.43$ & $18.82 \pm 4.66$ & 21.04 & $0.00 *$ \\
\hline Attentional & $17.1 \mid \pm 4.25$ & $17.40 \pm 4.87$ & $14.38 \pm 3.12$ & 15.31 & $0.00 *$ \\
\hline
\end{tabular}

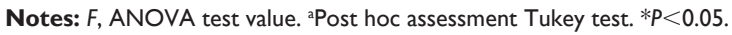

Abbreviations: BD-I, bipolar disorder I; BD-II, bipolar disorder II; ANOVA, analysis of variance; BIS-I I, Barrett Impulsiveness Scale-I I.

found to be statistically significantly higher in patients with BD-II $(F=15.31, P<0.00$; Table 4).

Patients with BD-I had lower scores than patients with BD-II in relations with friends, participation in social activities, daily activities and hobbies, and occupation subscales on the BDFQ $(P<0.05, P<0.05, P<0.01, P<0.01$, respectively). While the social withdrawal subscore was higher in patients with BD-II $(P<0.05)$, taking initiative and self-sufficiency subscores were higher in patients with BD-I $(P<0.05$; Table 5).

\section{Discussion}

The risk of suicide attempts among psychiatric disorders was identified as highest in patients with mood disorders $(60 \%)$. Twenty percent of those with BD die by suicide, as compared to $15 \%$ of those with major depressive disorder, $18 \%$ of those with alcoholism, $10 \%$ of those with schizophrenia, and $5 \%-10 \%$ of those with Axis II disorders. ${ }^{30,31}$ Thirtyeight (37.62\%) patients in our study had attempted suicide.

Table 5 Comparison of functioning in patients with BD-I and BD-II

\begin{tabular}{llllll}
\hline BDFQ & BD-I & BD-II & \multicolumn{2}{l}{ Statistics } \\
\cline { 5 - 6 } & $\mathbf{( N = 5 2 )}$ & $\mathbf{( N = 4 9 )}$ & $\boldsymbol{t}$ & P-value \\
\hline Emotional functioning & $3.62 \pm 1.13$ & $3.85 \pm 1.09$ & -0.9 & 0.52 \\
Intellectual functioning & $4.51 \pm 1.07$ & $4.22 \pm 1.04$ & 1.22 & 0.13 \\
Sexual functioning & $3.76 \pm 1.96$ & $3.97 \pm 2.09$ & -0.46 & 0.68 \\
Feelings of stigmatization & $3.19 \pm 2.23$ & $3.44 \pm 2.32$ & -0.5 & 0.56 \\
Social withdrawal & $2.88 \pm 1.61$ & $3.68 \pm 1.56$ & -2.26 & $0.03^{*}$ \\
Household relations & $6.16 \pm 2.89$ & $6.42 \pm 3.08$ & -0.38 & 0.86 \\
Relations with friends & $4.90 \pm 2.46$ & $6.75 \pm 2.45$ & -3.39 & $0.02^{*}$ \\
Participation to social & $7.47 \pm 3.50$ & $9.20 \pm 4.39$ & -1.97 & $0.04^{*}$ \\
activities & & & & \\
Daily activities and hobbies & $4.34 \pm 2.24$ & $6.35 \pm 3.70$ & -2.96 & $0.0 I^{* *}$ \\
Taking initiative and self & $2.62 \pm 1.44$ & $1.67 \pm 1.87$ & 2.22 & $0.03^{*}$ \\
sufficiency & & & & \\
Occupation & $4.42 \pm 1.48$ & $5.16 \pm 1.67$ & -2.03 & $0.0 I^{* *}$ \\
\hline
\end{tabular}

Note: ${ }^{*} P<0.05, * * P<0.01$.

Abbreviations: BDFQ, Bipolar Disorder Functioning Questionnaire; BD-l, bipolar disorder I; BD-II, bipolar disorder II; SD, standard deviation.
Of patients who attempted suicide, 23 (60.52\%) had BD-I and $15(39.47 \%)$ had BD-II. Increased suicide rates may contribute to a lower life expectancy and quality of life. Suicide attempt rates are 20-30 times higher in bipolar patients than general population..$^{32}$ In a study with bipolar and unipolar depressive disorder patients, high suicide risk was found in more than $52 \%$ of the patients and depressive anxiety symptoms, impulsivity, and hostility rates were higher in patients with high suicidality risk. ${ }^{33}$

The coexistence of a personality disorder is present in the majority of the patients who attempted suicide. In a controlled study of patients with $\mathrm{BD}$, a personality disorder diagnosis according to the DSM IV was present in $48 \%$ of bipolar patients. ${ }^{34}$ Given that the prevalence of personality disorders among the general population is about $5.9 \%$, personality disorder is significantly higher in patients with $\mathrm{BD}$ than general population. ${ }^{35}$ Patients with personality disorder were more likely to attempt suicide, ${ }^{36}$ both in our study and in the literature. ${ }^{37}$ Similarly, character traits are one of the many predictors for suicide attempts in patients with BD.

Studies examining the relationship between suicide attempts and temperament and character traits have shown that suicide attempters had lower $\mathrm{Sdi}^{32,33}$ and higher $\mathrm{ST}^{32-34}$ subscale scores within character dimension and higher HA, NS, and RD subscale scores ${ }^{11,35}$ within temperament dimension. Another study found a relationship between higher HA scores and suicide attempts in patients with BD. ${ }^{38}$ Consistent with the literature, in our study, NS1, NS2, HA4, and RD2 subscale scores are found to be higher and Sdi scores are found to be lower in patients with BD-I than BD-II and controls. For personality disorders, the rate of completed suicide has been identified as $29 \%-57 \% .{ }^{39}$ Slama et al ${ }^{40}$ have proposed that low Sdi and C scores could possibly predict the development of a personality disorder. In our study, lower Sdi and $\mathrm{C}$ scores in patients with BD-I than patients with BD-II and controls suggest that personality disorder coexistence may occur more frequently in patients with BD-I.

In the literature, suicide risk factors for patients with BD-I and BD-II include a family history of suicide attempts, early onset of $\mathrm{BD}$, frequent depressive symptoms, alcohol and substance abuse, social phobia features, antidepressant-induced mania, and a history of head trauma. No statistically significant differences were found in terms of suicide ideation and attempts between patients with BD-I and BD-II. ${ }^{41,42}$ Suicideattempt rates were higher in patients with $\mathrm{BD}$ compared to patients with unipolar depressive disorder. Suicide-attempt rates were also higher in patients with BD-II as compared to BD-I. ${ }^{42}$ However in our study, 23 (60.52\%) of 38 attempters 
had BD-I, and 15 (39.47\%) had BD-II. Other studies of BD patients have identified that unipolar patients had higher $\mathrm{NS}^{10}$ and lower $\mathrm{Sdi}^{6}$ scores compared to healthy controls. In a similar study, patients with BD had higher NS scores than patients with unipolar disorder and patients with bipolar and unipolar disorder had higher HA scores than healthy controls. ${ }^{15}$

In our study, within temperament dimension, NS1, NS2, HA4, and RD2 subscale scores were significantly higher in patients with BD-I than BD-II and healthy controls. Within character dimension, total Sdi scores, total C scores, and subscale scores for both dimensions were significantly lower in patients with BD-I than BD-II and healthy controls. In addition, total ST scores and ST subscale scores were significantly higher in patients with BD-II than BD-I and healthy controls. Because Slama et $\mathrm{al}^{40}$ considered $\mathrm{C}$ and Sdi scores as predictors of personality disorder, low $\mathrm{C}$ and Sdi scores in patients with BD-I suggest that the coexistence of personality disorder with $\mathrm{BD}$ could be more frequent in patients with BD-I. NS indicates a hereditary predisposition to exploratory activity in response to a new stimulus, impulsive decision making and irritability. ${ }^{12-14,38}$ Because in our study NS scores were higher in patients with BD-I, we may think that these patients may be more prone to impulsive behaviors like suicide.

Two main differences emerged in bipolar patients with and without a history of attempted suicide. One of these differences was that suicide attempters had more subjective depression and hopelessness, as well as more seriously suicidal ideations; they also displayed lifelong reactionary and aggressive tendencies. Patients who had attempted suicide were more impulsive in decision making and interpersonal relationships. ${ }^{43,44}$ Lifelong aggression levels were higher in patients with suicide attempts, but impulsivity levels were similar between the two groups. ${ }^{45}$ In our study, both motor and nonplanned impulsivity scores were higher in patients with BD-I than BD-II. In the manic phase, impulsivity is characterized by unplanned and motor impulsivity, whereas in the depressive phase, it is characterized again by unplanned impulsivity. Attentional impulsivity is present in BD-II. Impulsive behaviors such as suicide attempts usually occur in the depressive phase of BD. ${ }^{46,47}$ In our study, in concordance with literature, motor and nonplanned impulsivity was pronounced in patients with BD-I and attentional impulsivity was pronounced in patients with BD-II.

In the BDFQ, social withdrawal, relationships with friends, participation in social activities, daily activities and hobbies and occupation subscale scores were lower in patients with BD-I than BD-II, and only initiative-taking subscale scores were significantly higher in patients with BD-I than BD-II. BD adversely affects nearly every area of life and reduces overall functionality. ${ }^{48}$ Two studies investigating the differences between the psychosocial functioning of patients with BD-I and BD-II have shown that similar disabilities were present during both their euthymic and depressive periods. ${ }^{49,50} \mathrm{~A}$ recent meta-analysis showed similar levels of deterioration in cognitive functioning in euthymic patients with BD-I and BD-II. Euthymic patients with $\mathrm{BD}$ experience cognitive deficits, especially in executive functioning, working memory, and attention..$^{51}$ In our study, patients with BD-I had a more corrupted functionality in social activities and relationships than patients with BD-II.

\section{Study limitations}

Our study has several limitations, including its crosssectional design, the relatively small subject numbers, and the exclusive use of self-report questionnaires. Although it is not possible to establish direct causal relationships or determine predictive factors with these findings, our results are noteworthy in terms of being descriptive of the clinical characteristics of our patient population.

\section{Conclusion}

Suicide attempts in patients with BD-I and -II significantly affect individual's life and functionality. Early diagnosis, individual assessment of symptomatology, and the establishment of a treatment process are the most important factors. Our study has shown that impulsivity and risk of attempting suicide are higher in patients with BD-I than BD-II. In addition, patients with BD-I are found to have poorer functionality than patients with BD-II. High NS1, NS2, HA4, RD2 subscale scores and low Sdi and C scores may be related to suicide attempts. Higher motor and nonplanned impulsivity scores in patients with BD-I than BD-II suggest that these may be facilitating factors for an impulsive behavior like suicide. Identifying impulsivity, suicide attempts, temperament-character traits, and functionality in patients with BD-I and BD-II will be useful in the diagnosis and treatment of disease progression.

\section{Disclosure}

The authors report no conflicts of interest in this work.

\section{References}

1. Öztürk O, Ulusahin A. Ruh Sağlı̆gl ve Bozukluklarl-I (Mental Health and Disorder-I). 11.baskı. Ankara, Turkey: Hekimler Yayın Birliği; 2008.

2. Laursen TM. Life expectancy among persons with schizophrenia or bipolar affective disorder. Schizophr Res. 2011;131(1-3):101-104. 
3. American Psychiatric Association. Diagnostic and Statistical Manual of Mental Disorders. 4th ed. Text Revision. Washington, DC: American Psychiatric Association; 2000.

4. Tavormina G, Agius M. A study of the incidence of bipolar spectrum disorders in a private psychiatric practice. Psychiatr Danub. 2007; 19:370-374.

5. Hawton K, Sutton L, Haw C, Sinclair J, Harris L. Suicide and attempted suicide in bipolar disorder: a systematic review of risk factors. J Clin Psychiatry. 2005;66(6):693-704.

6. Dilsaver SC, Chen YW, Swann AC, Shoaib AM, Tsai-Dilsaver Y, Krajewski KJ. Suicidality, panic disorder and psychosis in bipolar depression, depressive-mania and pure-mania. Psychiatry Res. 1997;73(1-2): 47-56.

7. Novick DM, Swartz HA, Frank E. Suicide attempts in bipolar I and bipolar II disorder: a review and meta-analysis of the evidence. Bipolar Disord. 2010;12(1):1-9.

8. Schneider B, Wetterling T, Sargk D, Schneider F, Schnabel A, Maurer K. Axis I disorders and personality disorders as risk factors for suicide. Eur Arch Psychiatry Clin Neurosci. 2006;256:17-27.

9. Groholt B, Ekeberg O, Wichstrom L, Haldorsen T. Suicidal and nonsuicidal adolescents: different factors contribute to self-esteem. Suicide Life Threat Behav. 2005;35:525-535.

10. Frances A, Fyrer M, Clarkin J. Personality and suicide. Ann N Y Acad Sci. 1986;487:281-293.

11. Cloninger CR. A systematic method for clinical description and classification of personality variants: a proposal. Arch Gen Psychiatry. 1987; 44:573-588

12. Cloninger CR, Svrakic DM, Przybeck TR. A psychobiological model of temperament and character. Arch Gen Psychiatry. 1993;50:975-990.

13. Cloninger CR, Przybeck TR, Svrakic DM, Wetzel RD. The Temperament and Character Inventory (TCI): A Guide to its Development and Use. Vol. 16. Washington, DC: Department of Psychiatry, Center for Psychobiology of Personality, Washington University School of Medicine; 1994:120-125.

14. Köse S. [A psychobiological model of temperament and character: TCI]. Yeni Symposium Dergisi. 2003;41:86-97. Turkish.

15. Young LT, Bagby MR, Cooke RG, Parker JD, Levitt AJ, Joffe RT. A comparison of Tridimensional Personality Questionnaire dimensions in bipolar patients and unipolar depression. Psychiatry Res. 1995;58:139-143.

16. Osher Y, Lefkifker E, Kotler M. Low persistence in euthymic manicdepressive patients: a replication. J Affect Disord. 1999;53:87-90.

17. Strakowski SM, Stoll AL, Tohen M. TPQ as a predictor of six-month outcome in first episode mania. Psychiatr Res. 1993;48:1-8.

18. Rihmer Z, Akiskal KK, Rihmer A, Akiskal HS. Current research on affective temperaments. Curr Opin Psychiatry. 2010;23:12-18.

19. Pompili M, Innamorati M, Rihmer Z, et al. Cyclothymic-depressiveanxious temperament pattern is related to suicide risk in 346 patients with major mood disorders. J Affect Disord. 2012;136(3):405-411.

20. First MB, Spitzer RL, Gibbon M, Williams JB. Structured Clinical Interview for DSM-IV Axis I Disorders (SCID-I), Clinical Version. Washington, DC: American Psychiatric Press Inc; 1997.

21. Corapcioglu A, Aydemir O, Yildiz M. DSM-IV Eksen I Bozukluklari Için Yapilandirilmiş. Klinik Görüşme Kullanim Kilavuzu (SCID-I) (Structured Clinical Interview for DSM-IV, Clinical Version). Ankara, Turkey: Hekimler Yayın Birliği; 1999.

22. Köse S, Sayar K, Ak I. Mizaç ve Karakter Envanteri (Türkçe TCI): geçerlik, güvenirliği ve faktör yapisi [Turkish version of the Temperament and Character Inventory (TCI): reliability, validity, and factorial structure]. Klinik Psikofarmakoloji Bülteni. 2004;14(3):107-131. Turkish.

23. Patton JH, Stanford MS, Barratt ES. Factor structure of the Barratt impulsiveness scale. J Clin Psychol. 1995;51:768-774.

24. Güleç H, Tamam L, Gulec MY, et al. [Psychometric properties of Turkish version of BIS-11]. Klinik Psikofarmakoloji Bülteni. 2008;18: 251-258. Turkish.

25. Williams BW. A structured interview guide for Hamilton Depression Rating Scale. Arch Gen Psychiatr. 1978;45:742-747.
26. Akdemir A, Orsel S, Dag I, Turkcapar H, Iscan N, Ozbay H. Hamilton depresyon derecelendirme ölçeği (HDDÖ)'nin geçerliliği, güvenilirliği ve klinikte kullanımı [Hamilton Rating Scale for Depression (HRSD) 's validity, reliability and clinical use]. Psikiyatri Psikoloji Psikofarmakoloji Dergisi. 1996;4:251-259. Turkish.

27. Young RC, Biggs JT, Ziegler VE, Meyer DA. A rating scale for mania: reliability, validity and sensitivity. Br J Psychiatry. 1978; 133:429-435.

28. Karadag F, Oral ET, Aran Yalcın F, Eren E. Young Mani Derecelendirme Ölçeğinin Türkiye'de geçerlilik ve güvenilirliği [Young Mania Rating Scale reliability and validity in Turkey]. Türk Psikiyatri Dergisi. 2001;13:107-114. Turkish.

29. Aydemir O, Eren I, Savas H, et al. Bipolar bozuklukta işlevsellik ölçeğinin geliştirilmesi, güvenilirlik ve geçerliliği [Bipolar disorder scale development of functionality, reliability and validity]. Türk Psikiyatri Dergisi. 2007;18:344-352.32. Turkish.

30. Murphy GE. The of suicide in a life time risk alcholism. Arch Gen Psychiatry. 1990;47:383-392.

31. Frances A, Fyrer M, Clarkin J. Personality and suicide. Ann N Y Acad Sci. 1986;487:281-295.

32. Pompili M, Gonda X, Serafini G, et al. Epidemiology of suicide in bipolar disorders: a systematic review of the literature. Bipolar Disord. 2013;15(5):457-490.

33. Pompili M, Innamorati M, Raja M, et al. Suicide risk in depression and bipolar disorder: Do impulsiveness-aggressiveness and pharmacotherapy predict suicidal intent? Neuropsychiatr Dis Treat. 2008; 4(1):247-255.

34. Üçok A, Karaveli D, Kundakçı T, Yazıcı O. Comorbiditiy of personality disorder with bipolar mood disorder. Compr Psychiatry. 1998; 39:72-74.

35. Kessing LV. Recurrence in affective disorder. Effect of age and gender. Br J Psychiatry. 1998;172:29-34.

36. Ball J, Kearney B, Wilhelm K, Dewhurst-Savellis J, Barton B. Cognitive behaviour therapy and assertion training groups for patient with depression and comorbid personality disorders. Behav Cogn Psychother. 2000;28:71-85.

37. Leverich GS, Altshuler L, Frye MA, et al. Factors associated with suicide attempts in 648 patients with bipolar disorder in the Stanley Foundation Bipolar Network. J Clin Psychiatry. 2003;64(5):506-515.

38. Engström C, Brandström S, Sigvardsson S, Cloninger R, Nylander PO. Bipolar disorders II. Bipolar Disord. 2003;5:340-348.

39. Maris RW, Berman AL, Silverman MM. Comprehensive Textbook of Suicidology. New York, NY: The Guilford Press; 2000.

40. Slama F, Bellivier F, Henry C, et al. Bipolar patients with suicidal behavior: toward the identification of a clinical subgroup. J Clin Psychiatry. 2004;65(8):1035-1039.

41. Valtonen H, Suominen K, Mantere O, Leppämäki S, Arvilommi P, Isometsä ET. Suicidal ideation and attempts in bipolar I and II disorders J Clin Psychiatry. 2005;66(11):1456-1462.

42. Rihmer Z, Kiss K. Bipolar disorders and suicidal behaviour. Bipolar Disord. 2002;4(Suppl 1):21-25.

43. Simon TR, Swann AC, Powell KE, Potter LB, Kresnow M, O'Car-roll PW; Characteristics of impulsive suicide attempts and attempters. Suicide Life Threat Behav. 2001;32(Suppl 1):30-41.

44. Swann C, Donald M, Peggy J. Increased impulsivity associated with severity of suicide attempt history in patients with bipolar disorder. Am J Psychiatry. 2005;162:1680-1687.

45. Oquendo MA, Waternaux C, Brodsky B, et al. Suicidal behavior in bipolar mood disorder: clinical characteristics of attempters and nonattempters. J Affect Disord. 2000;59(2):107-117.

46. Wilson ST, Stanley B, Oquendo MA, Goldberg P, Zalsman G, Mann JJ. Comparing impulsiveness, hostility, and depression in borderline personality disorder and bipolar II disorder. J Clin Psychiatry. 2007; 68:1533-1539.

47. Goldberg JF, Perlis RH, Bowden CL, et al. Manic symptoms during depressive episodes in 1,380 patients with bipolar disorder: findings from the STEP-BD. Am J Psychiatry. 2009;166:173-181. 
48. Rosa AR, Reinares M, Michalak EE, et al. Functional impairment and disability across mood states in bipolar disorder. Value Health. 2010; 13:984-988.

49. Coryell W, Keller M, Endicott J, Andreasen N, Clayton P, Hirschfeld R. Bipolar II illness: course and outcome over a five-year period. Psychol Med. 1989;19(1):129-141.
50. Judd LL, Akiskal HS, Schettler PJ, et al. Psychosocial disability in the course of bipolar I and II disorders: a prospective, comparative, longitudinal study. Arch Gen Psychiatry. 2005;62:1322-1330.

51. Bora E, Yücel M, Pantelis C, Berk M. Meta analytic review of neurocognition in bipolar II disorder. Acta Psychiatr Scand. 2011;123: $165-174$.

\section{Publish your work in this journal}

Neuropsychiatric Disease and Treatment is an international, peerreviewed journal of clinical therapeutics and pharmacology focusing on concise rapid reporting of clinical or pre-clinical studies on a range of neuropsychiatric and neurological disorders. This journal is indexed on PubMed Central, the 'PsycINFO' database and CAS, and is the official journal of The International Neuropsychiatric Association (INA). The manuscript management system is completely online and includes a very quick and fair peer-review system, which is all easy to use. Visit http://www.dovepress.com/testimonials.php to read real quotes from published authors.

\footnotetext{
Submit your manuscript here: http://www.dovepress.com/neuropsychiatric-disease-and-treatment-journal
} 